\title{
Article \\ Control Strategy of Flywheel Energy Storage System Based on Primary Frequency Modulation of Wind Power
}

\author{
Yu Jia ${ }^{1,2} \oplus$, Zhenkui Wu ${ }^{1,2, *}$, Jihong Zhang ${ }^{1,2}$, Peihong Yang ${ }^{1,2}$ and Zilei Zhang ${ }^{1,2}$ \\ 1 School of Information Engineering, Inner Mongolia University of Science and Technology, \\ Baotou 014010, China; jiay@stu.imust.edu.cn (Y.J.); zjh00318@163.com (J.Z.); yph_1025@126.com (P.Y.); \\ zzl@imust.edu.cn (Z.Z.) \\ 2 Key Laboratory of Photothermal and Wind Power Generation in Inner Mongolia, Baotou 014010, China \\ * Correspondence: wuzk@imust.edu.cn
}

check for updates

Citation: Jia, Y.; Wu, Z.; Zhang, J.; Yang, P.; Zhang, Z. Control Strategy of Flywheel Energy Storage System Based on Primary Frequency Modulation of Wind Power. Energies 2022, 15, 1850. https://doi.org/ $10.3390 /$ en15051850

Academic Editor: Fabrice Locment

Received: 8 February 2022

Accepted: 1 March 2022

Published: 2 March 2022

Publisher's Note: MDPI stays neutral with regard to jurisdictional claims in published maps and institutional affiliations.

Copyright: (C) 2022 by the authors. Licensee MDPI, Basel, Switzerland. This article is an open access article distributed under the terms and conditions of the Creative Commons Attribution (CC BY) license (https:// creativecommons.org/licenses/by/ $4.0 /)$.

\begin{abstract}
As a form of energy storage with high power and efficiency, a flywheel energy storage system performs well in the primary frequency modulation of a power grid. In this study, a threephase permanent magnet synchronous motor was used as the drive motor of the system, and a simulation study on the control strategy of a flywheel energy storage system was conducted based on the primary frequency modulation of wind power. The speed and current double closed-loop control strategy was used in the system start-up phase, and the power and current double-closed-loop control strategy were used in the power compensation phase. The model reference adaptive control was used to accurately estimate the speed and position of the rotor. The system compensates for the wind power output by using a wind turbine in real-time and conducting simulation experiments to verify the feasibility of the charge and discharge control strategy. At the same time, it can be verified that the flywheel energy storage system has a beneficial effect on wind power frequency modulation.
\end{abstract}

Keywords: flywheel energy storage system; primary frequency modulation; charge and discharge control strategy; model reference adaptive control

\section{Introduction}

Under General Secretary Xi Jinping's important instructions to reach peak carbon dioxide emissions by 2030 and achieve carbon neutrality before 2060, many provinces in China have successively introduced new energy configuration storage plans. New energy and energy storage projects are rapidly spreading across the country. As of October 2021, China's cumulative installed capacity of renewable energy power generation exceeded 1 billion kilowatts, accounting for $43.5 \%$ of the country's total installed power generation capacity. In the future, new energy will maintain rapid development momentum. It is estimated that the installed capacity of wind power and solar power will reach 1.2 billion kilowatts or more in 2030, which will surpass coal power and become the main portion of installed capacity [1]. Whether it is the large-scale and intensive development of centralized new energy or the nearby consumption of distributed new energy, the support of energy storage technology is an inseparable component.

The flywheel energy storage system (FESS) has a large capacity, high energy conversion rate, high instantaneous power, and high-frequency charge and discharge characteristics. It has broad application prospects in grid frequency modulation, uninterrupted power supply, and kinetic energy recovery and reuse. At the same time, the FESS belongs to mechanical energy storage, which can fit perfectly with new energy configuration energy storage. Although most domestic FESSs are only commercial demonstrations, there will be significant room for improvement in the near future.

Many adaptive control methods have been studied, improved, and applied. For example, Ref. [2] presents a characteristic model-based all-coefficient adaptive control law on an experimental test rig for high-speed FESS suspended on active magnetic bearings. 
Ref. [3] presents an adaptive controller to provide failure compensation concerning a coaxial rotor helicopter to address the problem of instability due to rotor damage in a coaxial rotor helicopter. Ref. [4] presents an augmented subcutaneous model of type 1 diabetic patients by estimating the model parameters using the nonlinear least square method using the physiological data. Ref. [5] presents the coordinated control of the flywheel matrix system, which presents a neural-adaptive PID control algorithm to control each flywheel individually. Ref. [6] presents an immersion and invariance manifold adaptive controller to keep the constant DC-link voltage of FESS discharge in a wide speed range. Ref. [7] presents a controller, which is designed for the bidirectional Buck-Boost converter control in the FESS to improve the performance of FESS. Ref. [8] presents a stable, intelligent adaptive controller based on a recurrent fuzzy neural network for an induction machine-driven flywheel system. Ref. [9] presents an adaptive cut-off frequency for systems with multiple energy storage system units to realize several objectives simultaneously, including the stateof-charge limiting. Ref. [10] presents a novel adaptive control-based strategy for accurate simulation of solar panels under any given physical condition and for any general static or dynamic load. Ref. [11] presents an adaptive integral backstepping control scheme for tracking control of a 2- Degree of Freedom helicopter, which gives robustness to parameter uncertainties and unmodeled dynamics. Ref. [12] presents a model-free adaptive powerlevel control law for a nuclear superheated-steam supply system with forced primary circulation, which is free from physical and thermal-hydraulic parameters.

In this study, the FESS was used for the primary frequency modulation of the power grid. A three-phase permanent magnet synchronous motor (PMSM) was used as the drive motor, and a single FESS was used to compensate for wind power output by a wind turbine in real-time. The corresponding charging and discharging control strategy was proposed, and a simulation experiment of the FESS for wind power compensation was carried out.

\section{The Overall Structure of the System}

The FESS is usually composed of a drive motor, flywheel rotor, support bearing, and control system. As the core part of the system, the drive motor is a two-way motor: when the FESS is charging, the motor acts as an electric motor to drive the flywheel rotor to rotate; when the FESS is discharged, the motor acts as a generator for external power supply. The utilization rate of permanent magnet synchronous motors is the highest in the FESS, mainly because of its low rotor loss, high speed, and high operating efficiency. The material of the flywheel rotor has always been the focus of research, and the common ones are aluminum alloy, steel, glass fiber, etc. Currently, the support bearing part primarily uses magnetic suspension bearings in the high-speed field, such as high-temperature superconducting magnetic suspension bearings. Moreover, a good control system determines important factors, such as the rapid response and stability of the FESS [13-15]. The stored energy of a single FESS is directly determined by the moment of inertia and speed of the flywheel rotor, as shown in Equation (1):

$$
e=\frac{1}{2} J\left(\omega_{\max }-\omega_{\min }\right)^{2}
$$

Usually, $\omega_{\max }=2 \omega_{\min }$, So available:

$$
e=\frac{1}{8} J \omega_{\max }^{2}
$$

where $J$ is the moment of inertia of the flywheel rotor $\left(\mathrm{in} \mathrm{kg} \cdot \mathrm{m}^{2}\right), \omega$ is the speed of the flywheel rotor (in $\mathrm{rad} / \mathrm{s}$ ).

Although the FESS was originally developed for kinetic energy recovery and reuse, its advantages in grid frequency modulation have gradually been developed in recent years. Figure 1 shows the structure diagram of the FESS used for the primary frequency regulation of wind power. It can be seen that the output power of the wind turbine and the FESS forms a complementary mode and finally discharges stable power to the grid. 


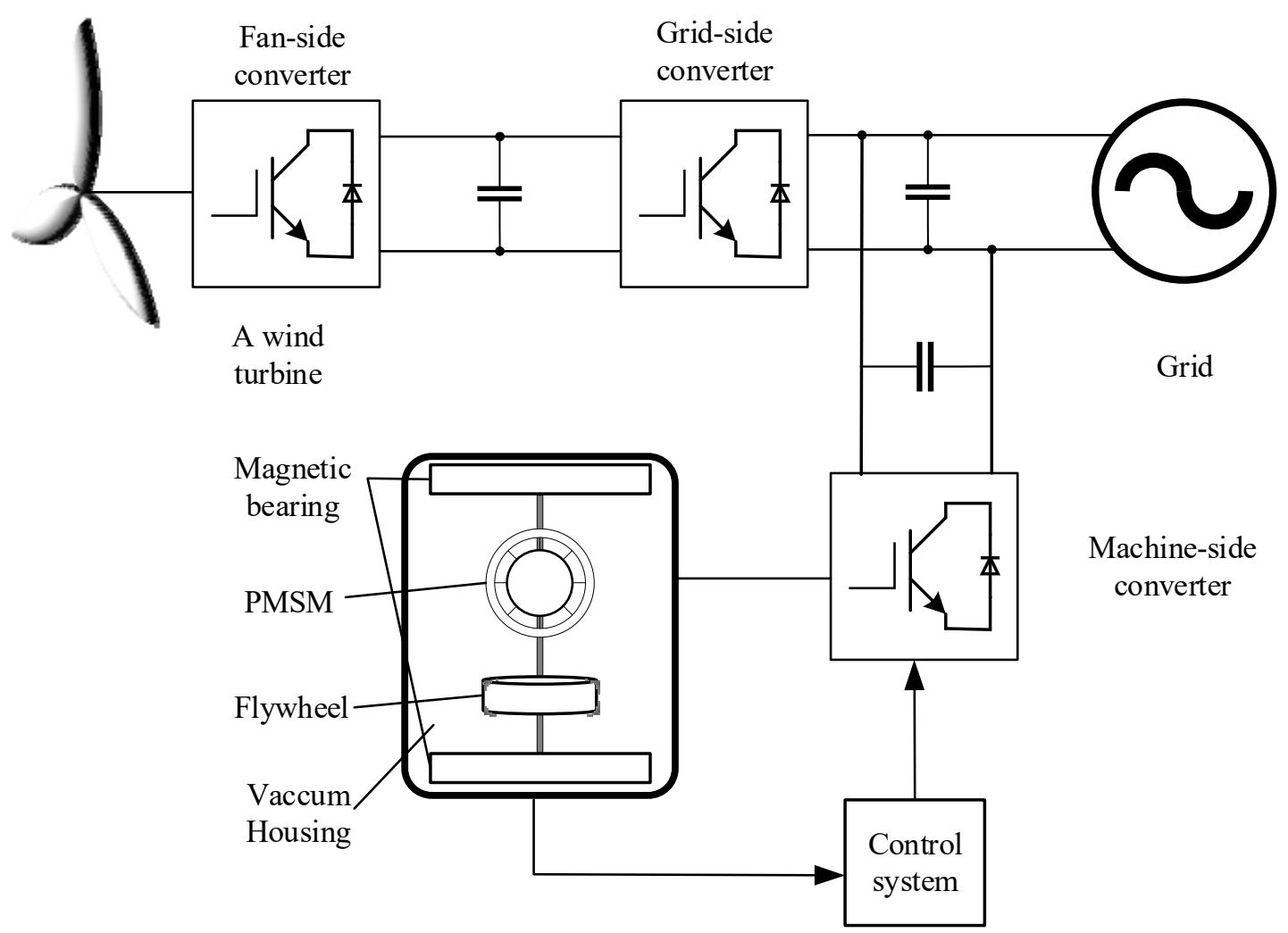

Figure 1. Structure diagram of FESS with wind power for frequency modulation.

\section{Modeling of FESS}

\subsection{Modeling of Pmsm}

For a three-phase PMSM, the relevant variables of the motor are usually directly used to establish a mathematical model. The following assumptions were made:

1. The current of the motor is a symmetrical three-phase sine wave.

2. The magnetic saturation of the motor core was ignored.

3. The eddy current and hysteresis loss in the motor was ignored.

Then, the mathematical model is established under the three-phase static coordinate system $[16,17]$, and the three-phase voltage is:

$$
\left[\begin{array}{l}
u_{a} \\
u_{b} \\
u_{c}
\end{array}\right]=\left[\begin{array}{lll}
R & 0 & 0 \\
0 & R & 0 \\
0 & 0 & R
\end{array}\right]\left[\begin{array}{l}
i_{a} \\
i_{b} \\
i_{c}
\end{array}\right]+\frac{d}{d t}\left[\begin{array}{l}
\varphi_{a} \\
\varphi_{b} \\
\varphi_{c}
\end{array}\right]
$$

where $R$ is the equivalent resistance of each stator winding of PMSM (in $\Omega$ ).

The flux equation in the three-phase stationary coordinate system is:

$$
\left[\begin{array}{l}
\varphi_{a} \\
\varphi_{b} \\
\varphi_{c}
\end{array}\right]=\left[\begin{array}{ccc}
L_{a a} & M_{a b} & M_{a c} \\
M_{b a} & L_{b b} & M_{b c} \\
M_{c a} & M_{c b} & L_{c c}
\end{array}\right]\left[\begin{array}{c}
i_{a} \\
i_{b} \\
i_{c}
\end{array}\right]+\varphi_{f}\left[\begin{array}{c}
\cos \theta_{e} \\
\cos \left(\theta_{e}-\frac{2 \pi}{3}\right) \\
\cos \left(\theta_{e}+\frac{2 \pi}{3}\right)
\end{array}\right]
$$

where $L$ is the self-inductance between the magnetic chains (in $\mathrm{H}$ ), $M$ is the mutual inductance between the magnetic chains (in $\mathrm{H}$ ), and $\theta_{e}$ is the spatial electrical angle of the angle between the $\mathrm{N}$ pole and the $\mathrm{A}$-axis (in rad).

$$
\left\{\begin{array}{c}
L_{a a}=L_{s 0}-L_{s 2} \cos 2 \theta_{e} \\
L_{b b}=L_{s 0}-L_{s 2} \cos 2\left(\theta_{e}-\frac{2 \pi}{3}\right) \\
L_{c c}=L_{s 0}-L_{s 2} \cos 2\left(\theta_{e}+\frac{2 \pi}{3}\right)
\end{array}\right.
$$




$$
\begin{gathered}
\left\{\begin{array}{c}
M_{a b}=M_{b a}=-M_{s 0}+M_{s 2} \cos 2\left(\theta_{e}+\frac{\pi}{6}\right) \\
M_{b c}=M_{c b}=-M_{s 0}+M_{s 2} \cos 2\left(\theta_{e}-\frac{\pi}{2}\right) \\
M_{c a}=M_{a c}=-M_{s 0}+M_{s 2} \cos 2\left(\theta_{e}+\frac{5 \pi}{6}\right)
\end{array}\right. \\
\left\{\begin{array}{c}
L_{s 0}=\frac{\varphi_{a}}{i_{a}}+\frac{L_{a a d}+L_{a a q}}{2} \\
L_{s 2}=\frac{L_{a a q}-L_{a a d}}{2} \\
M_{s 0}=\frac{L_{a a d}+L_{a a q}}{4} \\
M_{s 2}=\frac{4}{2}-L_{a a d}
\end{array}\right.
\end{gathered}
$$

The electromagnetic torque equation under the three-phase static coordinate system is:

$$
T_{e}=-n_{p}\left[\begin{array}{lll}
i_{a} & i_{b} & i_{c}
\end{array}\right]\left(A\left[\begin{array}{c}
i_{a} \\
i_{b} \\
i_{c}
\end{array}\right]-\varphi_{f}\left[\begin{array}{c}
\sin \theta_{e} \\
\sin \left(\theta_{e}-\frac{2 \pi}{3}\right) \\
\sin \left(\theta_{e}+\frac{2 \pi}{3}\right)
\end{array}\right]\right)
$$

where

$$
A=\left[\begin{array}{ccc}
-L_{s 2} \sin 2 \theta_{e} & M_{s 2} \sin 2\left(\theta_{e}+\frac{\pi}{6}\right) & M_{s 2} \sin 2\left(\theta_{e}+\frac{5 \pi}{6}\right) \\
M_{s 2} \sin 2\left(\theta_{e}+\frac{\pi}{6}\right) & -L_{s 2} \sin 2\left(\theta_{e}-\frac{2 \pi}{3}\right) & M_{s 2} \sin 2\left(\theta_{e}-\frac{\pi}{2}\right) \\
M_{s 2} \sin 2\left(\theta_{e}+\frac{5 \pi}{6}\right) & M_{s 2} \sin 2\left(\theta_{e}-\frac{\pi}{2}\right) & -L_{s 2} \sin 2\left(\theta_{e}-\frac{2 \pi}{3}\right)
\end{array}\right]
$$

It can be seen from the above formula that the mathematical models under the threephase stationary coordinate system are very complicated, so they are usually transformed into mathematical models under the two-phase rotating coordinate system, as shown in the following Equation:

$$
\left[\begin{array}{l}
u_{d} \\
u_{q}
\end{array}\right]=\left[\begin{array}{cc}
R & -\omega_{e} L_{q} \\
\omega_{e} L_{d} & R
\end{array}\right]\left[\begin{array}{l}
i_{d} \\
i_{q}
\end{array}\right]+P\left[\begin{array}{c}
L_{d} i_{d}+\varphi_{f} \\
L_{q} i_{q}
\end{array}\right]+\left[\begin{array}{c}
0 \\
\omega_{e} \varphi_{f}
\end{array}\right]
$$

The electromagnetic torque equation is:

$$
T_{e}=1.5 n_{p}\left[\varphi_{f} i_{q}+\left(L_{d}-L_{q}\right) i_{d} i_{q}\right]
$$

The Equation of motion is:

$$
\begin{gathered}
J \cdot P \omega_{m}=T_{e}-T_{L}-B \omega_{m} \\
P \theta=\omega_{e}=n_{p} \omega_{m}
\end{gathered}
$$

where $P$ is the differential operator, $\omega_{e}$ is the electrical angular velocity (in $\mathrm{rad} / \mathrm{s}$ ), $\omega_{m}$ is the mechanical angular velocity (in rad/s), $n_{p}$ is the number of pole pairs, $L_{d}$ and $L_{q}$ are the inductances (in $\mathrm{H}), \varphi_{f}$ is the permanent magnet link (in $\mathrm{Wb}$ ), $T_{e}$ is the electromagnetic torque (in $\mathrm{N} \cdot \mathrm{m}$ ), $T_{L}$ is the no-load torque (in $\mathrm{N} \cdot \mathrm{m}$ ), and $B$ is the damping coefficient.

\subsection{Modeling of Position Sensor-Less Control}

Owing to the special design of the flywheel rotor in the FESS, it is impossible to install a position sensor in the PMSM. Therefore, position sensor-less technology was used to estimate the speed and position of the flywheel rotor. This study uses a model reference adaptive control (MRAS) to estimate the speed and position of the flywheel rotor.

The MRAS used in FESS mainly comprises a reference model, an adjustable model, and an adaptive law. The basic idea of its estimation is to use the actual motor model as a reference, input the d-axis and q-axis voltage and motor current output into the adjustable model, and feedback the speed calculated by the adaptive law to the adjustable model to reduce error. Therefore, the speed and position of the rotor can be accurately estimated [18-20]. A specific working principle diagram is presented in Figure 2. 


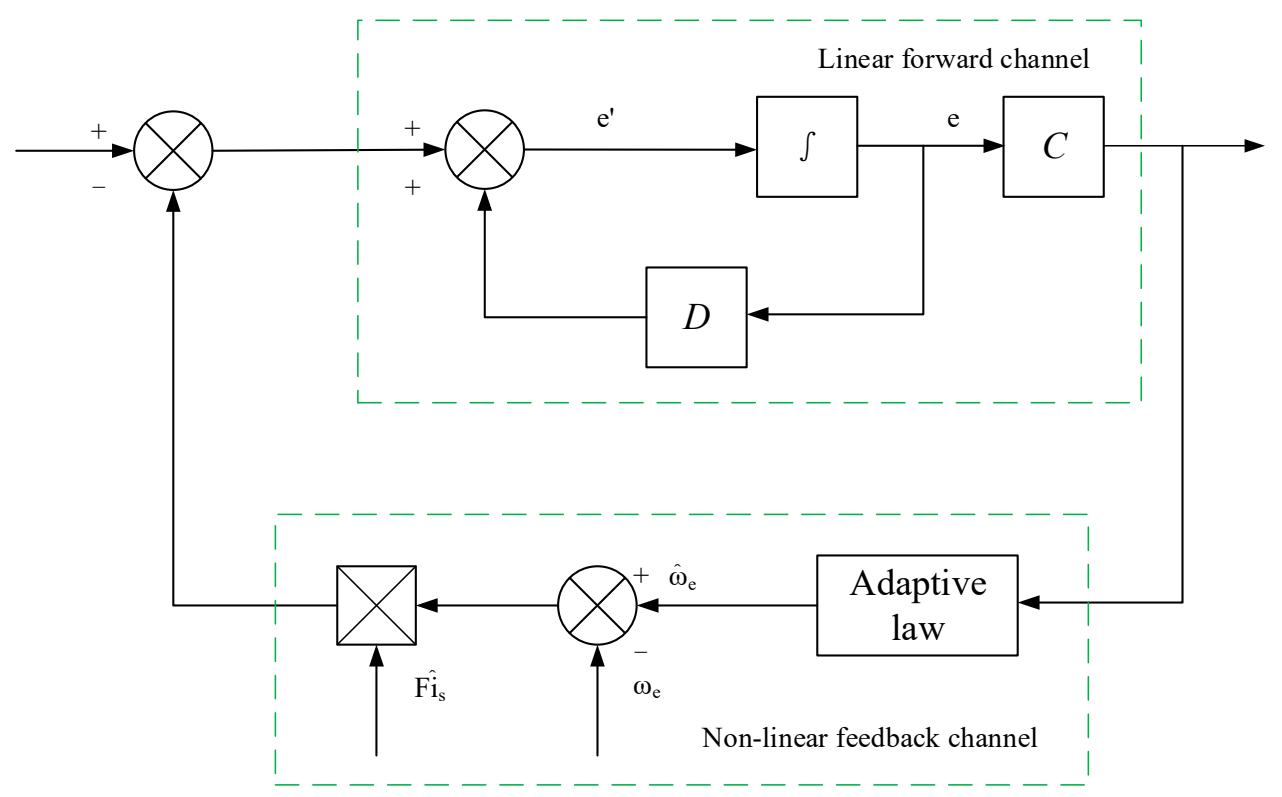

Figure 2. The working principle diagram of MRAS.

In this diagram, $D=\left[\begin{array}{cc}-\frac{R}{L_{d}} & \omega_{e} \frac{L_{q}}{L_{d}} \\ -\omega_{e} \frac{L_{d}}{L_{q}} & -\frac{R}{L_{q}}\end{array}\right], C=I=\left[\begin{array}{ll}1 & 0 \\ 0 & 1\end{array}\right], F=\left[\begin{array}{cc}0 & \frac{L_{q}}{L_{d}} \\ -\frac{L_{d}}{L_{q}} & 0\end{array}\right]$, $e=i^{*}-\hat{i}^{*},{ }^{*}$ means the variable's real value.

Among them, for the linear forward channel, it is only necessary to satisfy the zero and pole of the transfer function in the left half plane of the $S$. For the nonlinear feedback channel, it is necessary to satisfy the POPOV superstability theorem. According to the working principle diagram of the MRAS, its control structure diagram can be obtained in Figure 3, and in this circumstance, the stability of the system model can be further calculated.

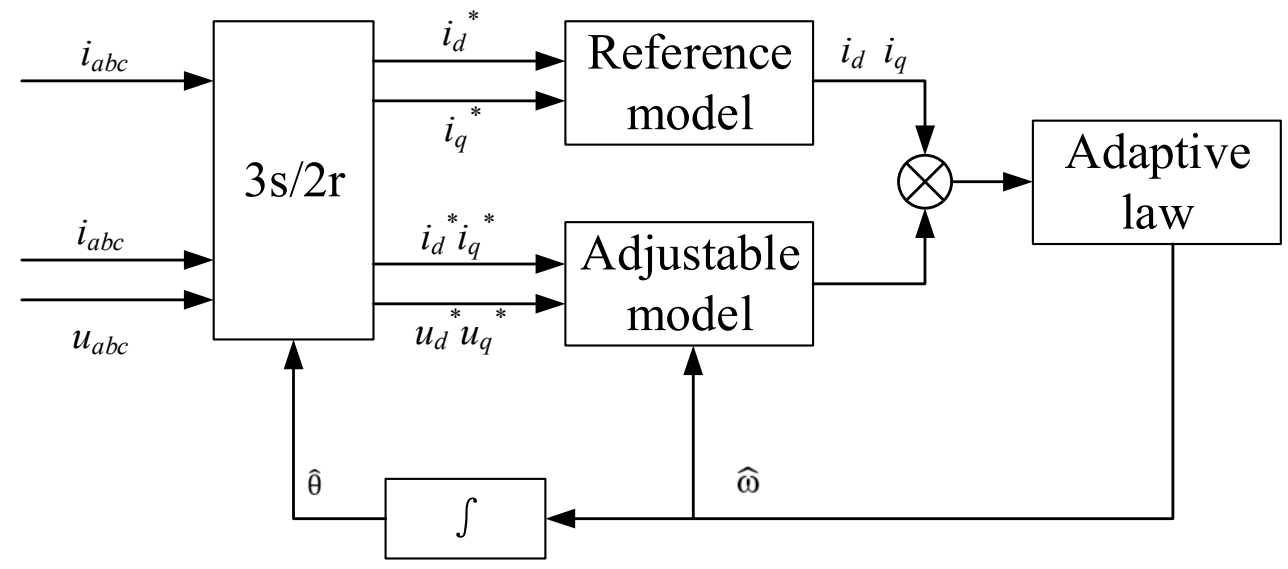

Figure 3. The control structure diagram of MRAS.

where the $i_{a b c}$ and $u_{a b c}$ are obtained from the PMSM. Meanwhile, the current and voltage in the three-phase stationary coordinate system are converted into the current and voltage in the two-phase rotating coordinate system through the ' $3 \mathrm{~s} / 2 \mathrm{r}$ ' module. The reference model is the model of the drive motor itself (refer to Equations (9)-(12)), and its voltage equation is changed to the following form:

$$
\frac{d}{d t}\left[\begin{array}{c}
i_{d}+\frac{\varphi_{f}}{L_{d}} \\
i_{q}
\end{array}\right]=D \cdot\left[\begin{array}{c}
i_{d}+\frac{\varphi_{f}}{L_{d}} \\
i_{q}
\end{array}\right]+\left[\begin{array}{c}
\frac{u_{d}}{L_{d}}+\frac{R \varphi_{f}}{L_{d}^{2}} \\
\frac{u_{q}}{L_{q}}
\end{array}\right]
$$


And assuming a new set of variables as: $i_{d}^{*}=i_{d}+\frac{\varphi_{f}}{L_{d}}, i_{q}^{*}=i_{q}, u_{d}^{*}=u_{d}+R \frac{\varphi_{f}}{L_{d}}, u_{q}^{*}=u_{q}$. Therefore,

$$
\frac{d}{d t}\left[\begin{array}{l}
i_{d}^{*} \\
i_{q}^{*}
\end{array}\right]=D \cdot\left[\begin{array}{c}
i_{d}^{*} \\
i_{q}^{*}
\end{array}\right]+\left[\begin{array}{c}
\frac{u_{d}^{*}}{L_{d}} \\
u_{q}^{*} \\
\overline{L_{q}}
\end{array}\right]
$$

The equation of the adjustable model with angular frequency as the adjustable parameter is obtained as follows:

$$
\frac{d}{d t}\left[\begin{array}{c}
\hat{i}_{d}+\frac{\psi_{f}}{L_{d}} \\
\hat{i}_{q}
\end{array}\right]=\hat{D} \cdot\left[\begin{array}{c}
\hat{i}_{d}+\frac{\psi_{f}}{L_{d}} \\
\hat{i}_{q}
\end{array}\right]+\left[\begin{array}{c}
\frac{u_{d}^{*}}{L_{d}} \\
\frac{u_{q}^{*}}{L_{q}}
\end{array}\right]
$$

The above operation is repeated to get the final adjustable model:

$$
\frac{d}{d t}\left[\begin{array}{l}
\hat{i}_{d}^{*} \\
\hat{i}_{q}^{*}
\end{array}\right]=\hat{D} \cdot\left[\begin{array}{c}
\hat{i}_{d}^{*} \\
\hat{i}_{q}^{*}
\end{array}\right]+\left[\begin{array}{c}
\frac{u_{d}^{*}}{L_{d}} \\
u_{q}^{*} \\
\overline{L_{q}}
\end{array}\right]
$$

According to the POPOV superstability theorem, to stabilize the error system, the following two conditions must be met simultaneously:

1. The transfer function of the system, which is $G(s)=C(s I-D)^{-1}$, is positive definite 2. The nonlinear time-invariant link must satisfy the POPOV integral inequality.

$$
\mu\left(0, t_{1}\right)=\int_{0}^{t_{1}}\left(\hat{\omega}_{e}-\omega_{e}\right) e^{T} F \hat{i}^{*} d t \geq-\varepsilon^{2}
$$

where $\varepsilon$ is a limited number of the normal.

After bringing $C$ and $D$ into $G(s)$, it is easy to conclude that $G(s)$ is a positive definite. As for the POPOV integral inequality, assuming $f_{1}, f_{2}$ and $h(t)$ as:

$$
\left\{\begin{aligned}
f_{1}(v, t) & =k_{1} e^{T} F \hat{i}^{*} \\
f_{2}(v, t) & =k_{2} e^{T} F \hat{i}^{*} \\
h(t) & =e^{T} F \hat{i}^{*}
\end{aligned}\right.
$$

And considering the adaptive law of the motor speed as:

$$
\hat{\omega}_{e}=\int_{0}^{t} f_{1}(v, t, \tau) d \tau+f_{2}(v, t)+\hat{\omega}(0)
$$

Substituting Equation (19) into Equation (17) yields:

$$
\begin{aligned}
& \mu\left(0, t_{1}\right)=\int_{0}^{t_{1}} e^{T}\left(\int_{0}^{t} f_{1}(v, t, \tau) d \tau+f_{2}(v, t)+\hat{\omega}(0)-\omega\right) F \hat{i}^{*} d t \\
& =\int_{0}^{t_{1}} e^{T} F \hat{i}^{*}\left(\int_{0}^{t} f_{1}(v, t, \tau) d \tau+\hat{\omega}(0)-\omega\right) d t+\int_{0}^{t_{1}} e^{T} F \hat{i}^{*} f_{2}(v, t) d t
\end{aligned}
$$

Split the Equation (20) into $\mu_{1}=\int_{0}^{t_{1}} e^{T} F \hat{i}^{*}\left(\int_{0}^{t} f_{1}(v, t, \tau) d \tau+\hat{\omega}(0)-\omega\right) d t$ and $\mu_{2}=$ $\int_{0}^{t_{1}} e^{T} F \hat{i}^{*} f_{2}(v, t) d t$

Assuming $k_{1} H(t)=\int_{0}^{t} f_{1}(v, t, \tau) d \tau+\hat{\omega}(0)-\omega$, from the formula $\int_{0}^{t_{1}} h(t) d H(t)=$ $\frac{1}{2}\left[H^{2}\left(t_{1}\right)-H^{2}(0)\right] \geq-\frac{1}{2} H^{2}(0)$, it can be deduced that

$$
\left\{\begin{array}{c}
\mu_{1}=k_{1} \int_{0}^{t_{1}} h(t) \cdot \mathrm{H}(\mathrm{t}) d t \geq-\varepsilon^{2} \\
\mu_{2}=\int_{0}^{t_{1}} h(t) f_{2}(v, t) d t=k_{2} \int_{0}^{t_{1}}(h(t))^{2} d t \geq 0
\end{array}\right.
$$

To conclude, $\mu \geq-\varepsilon^{2}$. 
The estimated rotor speed can be expressed as:

$$
\hat{\omega}_{e}=\hat{\omega}_{e}(0)+\left(k_{p}+\frac{k_{i}}{s}\right)\left[\left(\frac{L_{q}}{L_{d}} i_{d}^{*} \hat{i}_{q}-\frac{L_{d}}{L_{q}} i_{q}^{*} \hat{i}_{d}\right)+\left(\frac{L_{d}}{L_{q}}-\frac{L_{q}}{L_{d}}\right) \hat{i}_{d} \hat{i}_{q}+\left(\hat{i}_{q}-i_{q}^{*}\right) \frac{\varphi_{f}}{L_{q}}\right]
$$

where $k_{p}$ and $k_{i}$ are the proportional and integral coefficients, respectively.

The estimated rotor position can be expressed as:

$$
\hat{\theta}=\int_{0}^{t} \hat{\omega}_{e} d t
$$

\subsection{Modeling of Power Compensation Control Strategy}

In this study, a hidden-pole three-phase PMSM and a vector control strategy with $i_{d}=0$ were used. With this method, only the quadrature axis current component in the stator current needs to be controlled to realize the charge and discharge control of the FESS.

In the FESS start-up phase, the control system uses the control strategy of the outer speed and inner current loops, and the rotor speed quickly increases to the charging and discharging starting speed $(3000 \mathrm{rpm})$. After the system starts, the speed of the flywheel rotor remains unchanged when entering the power compensation phase.

With the FESS in the power compensation phase, the control strategy of the power outer and current inner loops was used to perform real-time peak shaving for the power curve output by a wind turbine. When wind power is too great, the FESS uses the excess power to charge up; contrarily, the FESS compensates for fluctuating and/or extremely low wind power by discharging power more smoothly to the grid [21-25]. The FESS flow chart for the real-time compensation of wind power output by a wind turbine is shown in Figure 4. During the entire process, the FESS relies on the characteristics of rapid charging and discharging to achieve rapid real-time compensation for wind power. The FESS control block diagram based on wind power frequency modulation is shown in Figure 5.

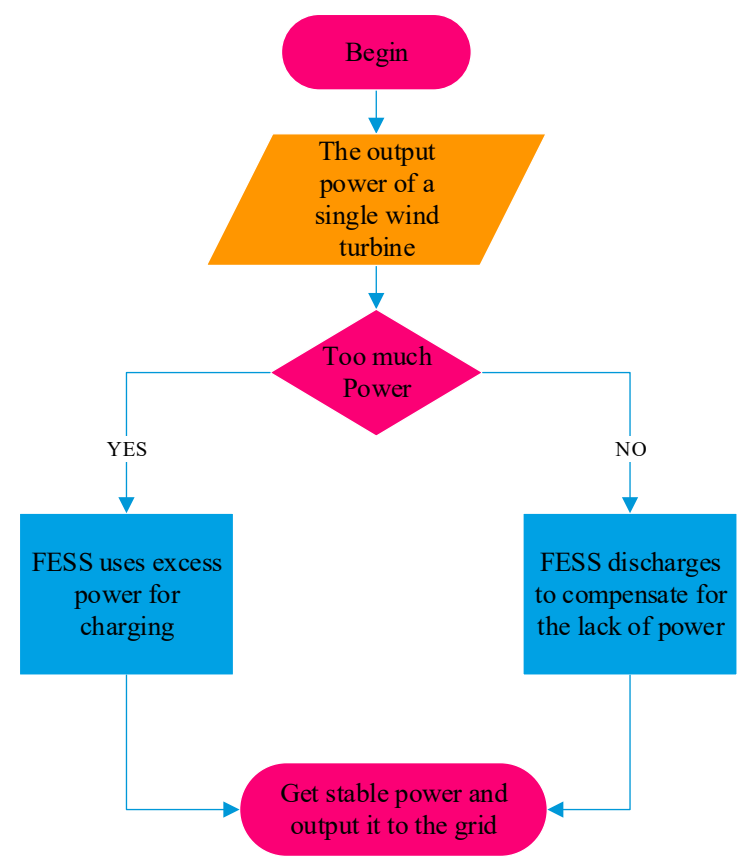

Figure 4. Wind power compensation flow chart. 


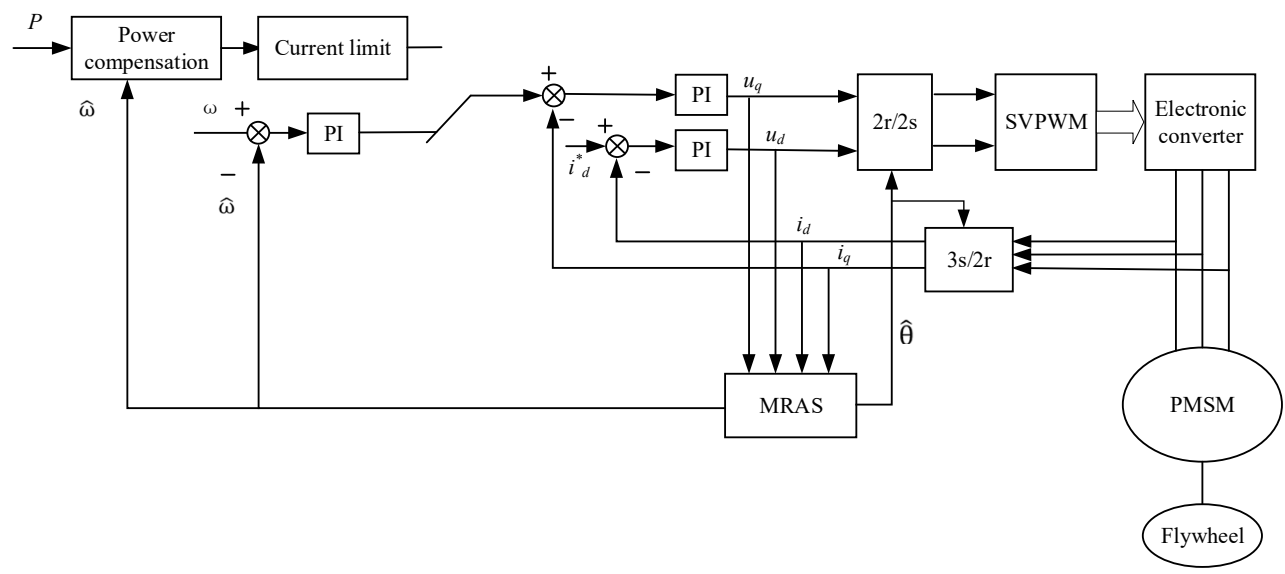

Figure 5. FESS control block diagram based on wind power frequency modulation.

In the power outer loop control in Figure 5, the adjusted smooth wind power under ideal conditions is simulated according to the wind power output by a wind turbine, and the output power that needs to be compensated is obtained after the difference between the two. Calculate the specific value of $i_{q}$ according to $i_{q}=\frac{9550 \cdot P}{1.5 n_{p} \cdot \varphi_{f} \cdot \hat{\omega}_{n}}$, and then input it to the current inner loop. At the same time, to ensure that the flywheel works within the safe range (3000-6000 rpm), the system is guaranteed to work within the safe range by limiting the $i_{q}$ input to the current inner loop.

\section{Power Compensation Simulation}

In the simulation, the actual wind power output of a wind turbine was used for compensation. The specific value of the wind power was measured every minute, and the 51-min variable wind power was used as the wind power that requires compensation. In the simulation, the speed of the flywheel during the power compensation phase was $3000-6000 \mathrm{rpm}$, the moment of inertia of the flywheel rotor was $72.95 \mathrm{~kg} \cdot \mathrm{m}^{2}$, the selfdispersion rate of the system was $2 \%$ of the rated power, and the single-rated power of the FESS was $26 \mathrm{~kW}$. The stand-alone energy storage capacity is $3.6 \mathrm{MJ}$, and the discharge depth is $75 \%$. The system completes the start-up phase after $555 \mathrm{~s}$, keeping the original speed unchanged, and entering the power compensation phase at $600 \mathrm{~s}$, with a simulation time of $3600 \mathrm{~s}$. The relevant parameters of the three-phase PMSM used are shown in Table 1. The wind power curve output by a wind turbine is shown in Figure 6, and the simulation model is shown in Figure 7 [26-28].

Table 1. The relevant parameters of PMSM.

\begin{tabular}{ccc}
\hline Unit & Parameter & Value \\
\hline$\Omega$ & Stator resistance & 0.0485 \\
\hline $\mathrm{mH}$ & d-axis inductance & 0.395 \\
\hline $\mathrm{mH}$ & q-axis inductance & 0.395 \\
\hline $\mathrm{N} \cdot \mathrm{m}$ & Rated torque & 42.09 \\
\hline $\mathrm{Wb}$ & Permanent magnet link & 0.1194 \\
\hline$/$ & Number of pole pairs & 4 \\
\hline $\mathrm{N} \cdot \mathrm{m}$ & No-load torque & 0.8 \\
\hline $\mathrm{V}$ & DC side voltage & 800 \\
\hline
\end{tabular}




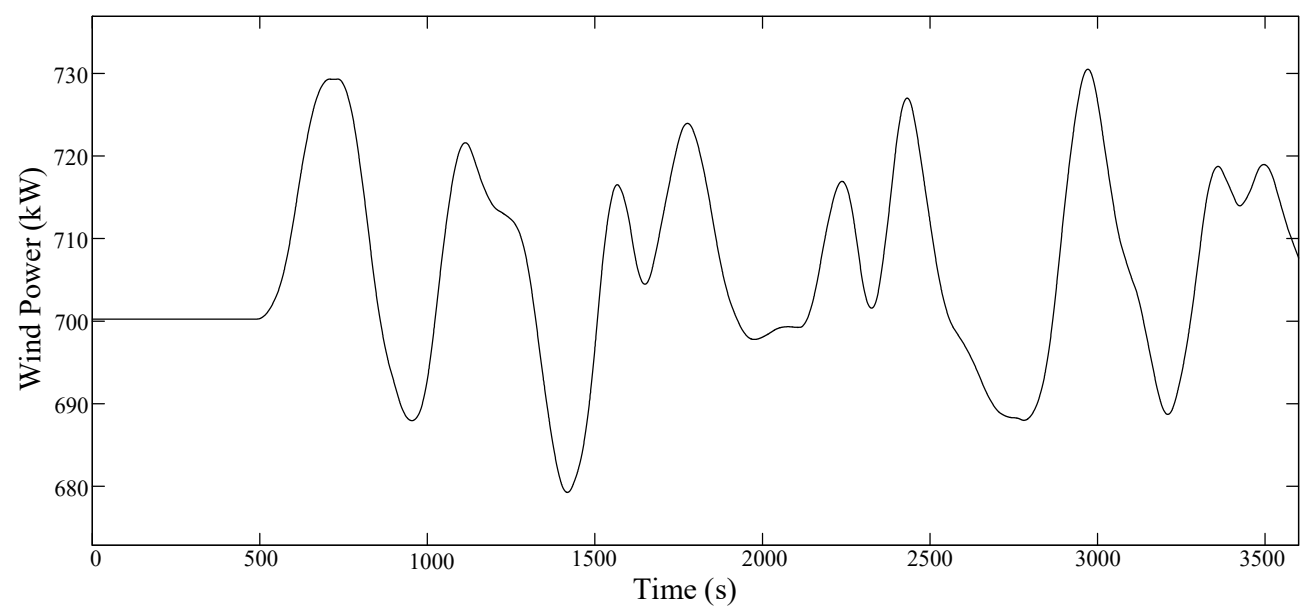

Figure 6. The wind power curve output by a single wind turbine.

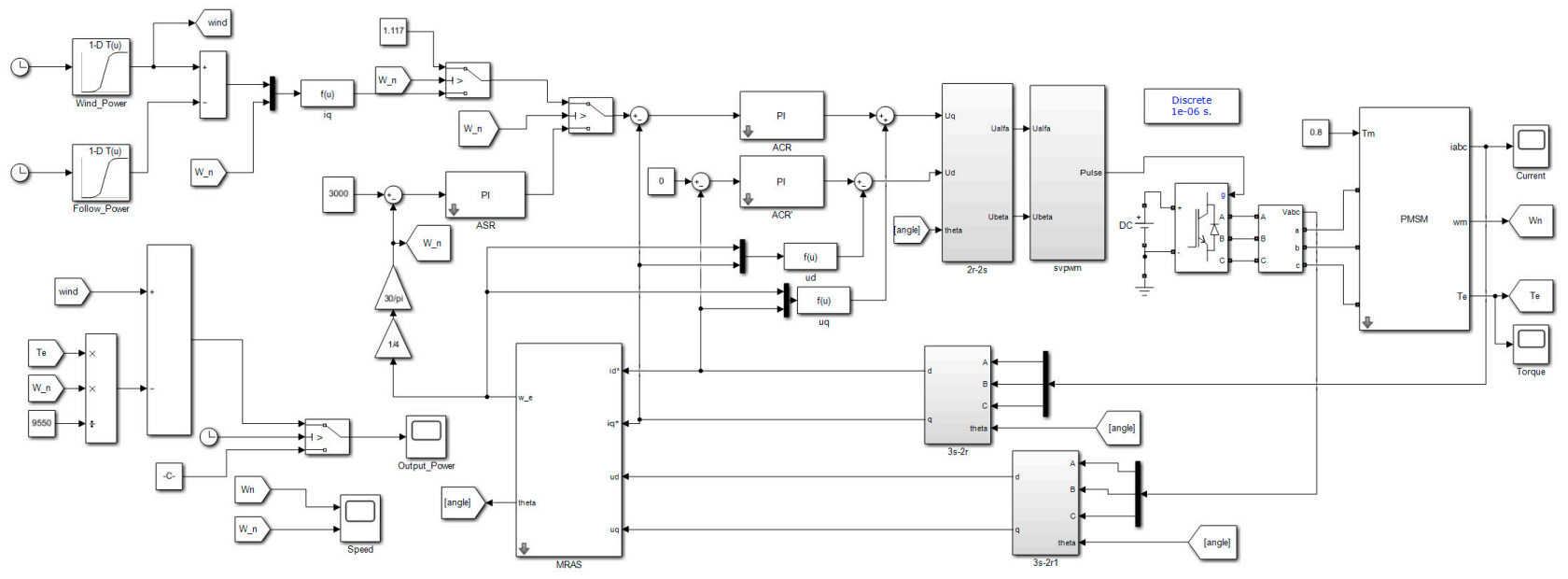

Figure 7. Power compensation simulation model of FESS.

In Figure 7 , the start-up phase is the maximum speed of $3000 \mathrm{rpm}$, and $i_{q}$ is obtained through the speed regulator (module ASR). In the power compensation stage, the module 'Wind Power' is the wind power output by the wind turbine, and the module 'Follow Power' is the adjusted power obtained under ideal conditions. The current value required to compensate the power is calculated from the rotational speed $\hat{\omega}_{n}$ estimated by the module 'MRAS', and the current is limited to ensure that the work is within a safe range. $i_{d}$ and $i_{q}$ get $u_{d}$ and $u_{q}$ through the current regulator (module ACR). The module ' $2 \mathrm{r}-2 \mathrm{~s}$ ' converts the variables in the two-phase rotating coordinate system into the variables in the two-phase stationary coordinate system. The module 'SVPWM' is used to output the pulse signal to the power electronic converter to control the operation of the PMSM. Modules ' $3 s-2 r$ ' are used to convert the variables in the three-phase stationary coordinate system into the variables in the two-phase rotating coordinate system. In the model, the $u_{a b c}$ and $i_{a b c}$ output by the PMSM are converted into $u_{d}, u_{q}$ and $i_{d}, i_{q}$, which are further given to the module 'MRAS' to estimate the PMSM's rotational speed, thereby obtaining the estimated rotational speed $\hat{\omega}_{n}$ and the estimated rotor position $\hat{\theta}$.

The experiment realized compensations as high as 51 times/hour and effectively compensated the fluctuating wind power curve into a relatively smooth curve. Figure 8 shows the power curve after FESS compensation. Compared with the wind power output by a wind turbine, the wind power compensated by FESS is approximately $703 \mathrm{~kW}$, and the overall power fluctuation range does not exceed 3\%. Figure 9 shows a waveform diagram of the flywheel rotor speed. During the compensation process, the flywheel rotor speed was maintained at 3000-6000 rpm. 


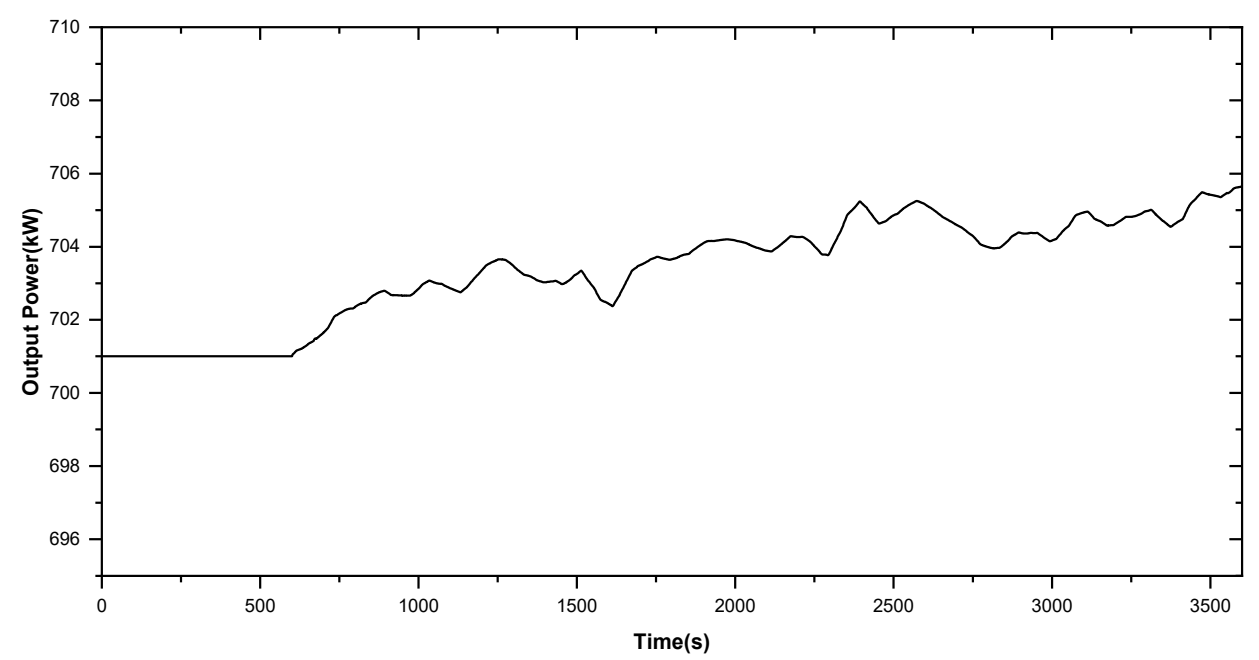

Figure 8. The power curve after FESS compensation.

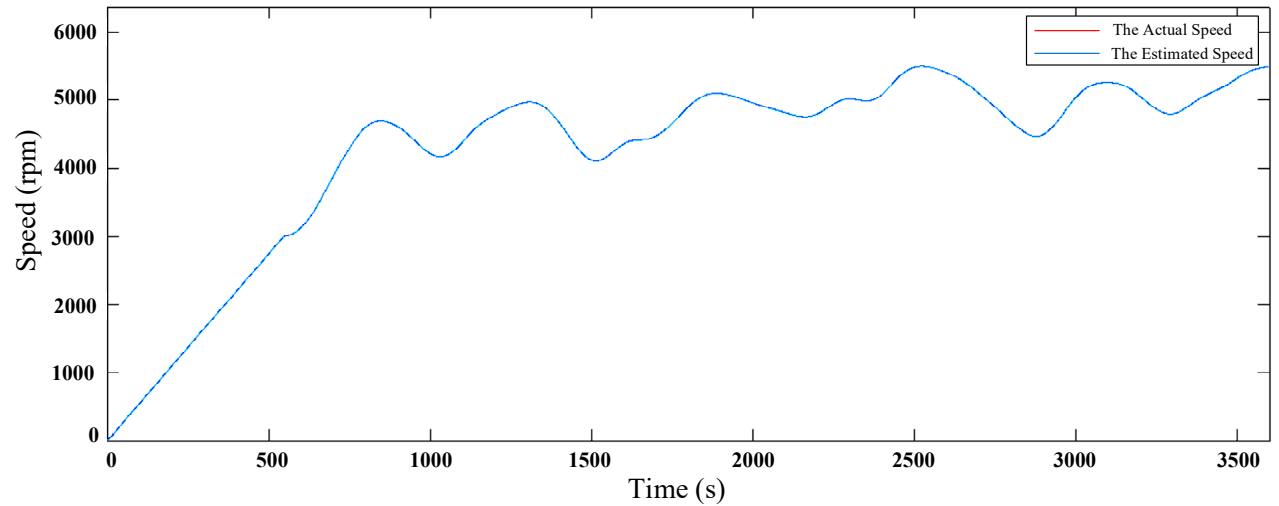

Figure 9. The waveform diagram of the flywheel rotor speed.

Figure 10 shows an enlarged part of the speed waveform. In the figure, it can be seen that the error between the estimated speed and the actual speed does not exceed $0.5 \%$. Therefore, the results using the MRAS to estimate the speed are reliable.

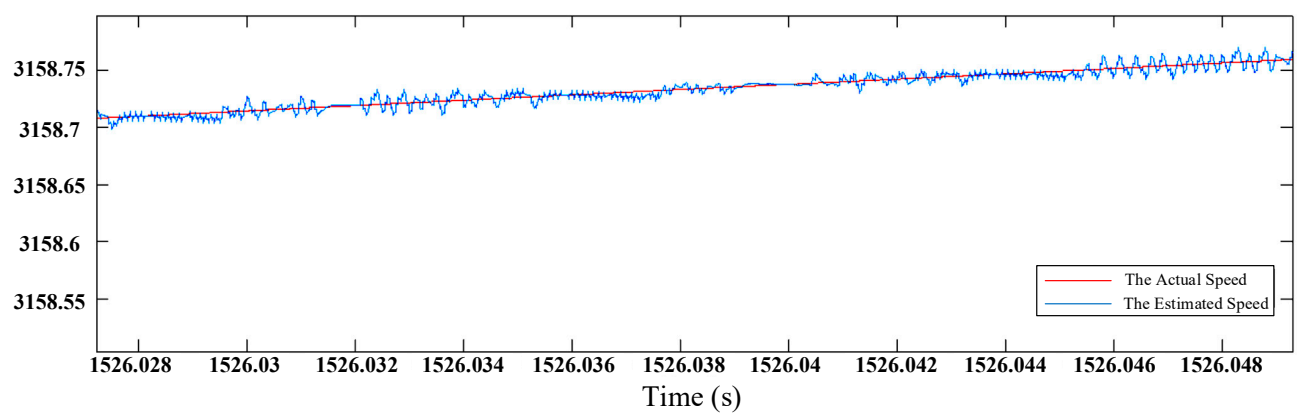

Figure 10. The enlarged part of the speed waveform.

Figure 11 shows the electromagnetic torque waveform of the PMSM. It can be seen from the figure that the general trend of the electromagnetic torque is basically consistent with the wind power curve that needs adjustment. 


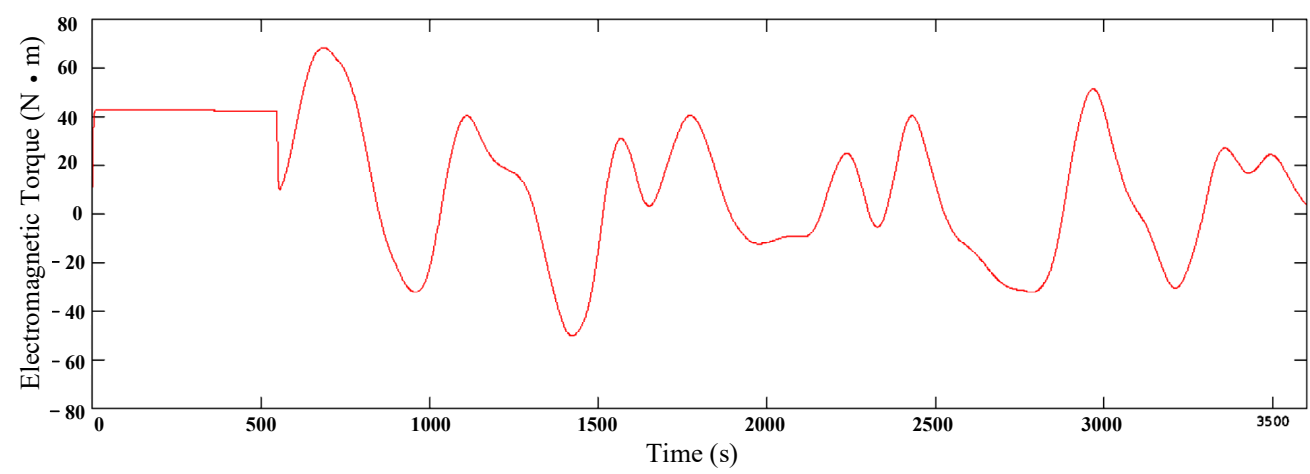

Figure 11. The electromagnetic torque waveform of the PMSM.

Figure 12 shows the three-phase current waveform, and the change in the current size is basically the same as the change in the size of the electromagnetic torque. Figure 13 shows the enlarged part of the current waveform, and it can be seen that the current fluctuation is very small, the period is approximately $0.51 \mathrm{~s}$, and the initial phase angle is $0 \mathrm{rad}$. The amplitude of the current in the start-up phase is approximately $62.72 \mathrm{~A}$. In the power compensation phase, the amplitude of the three-phase alternating current changes with the torque.

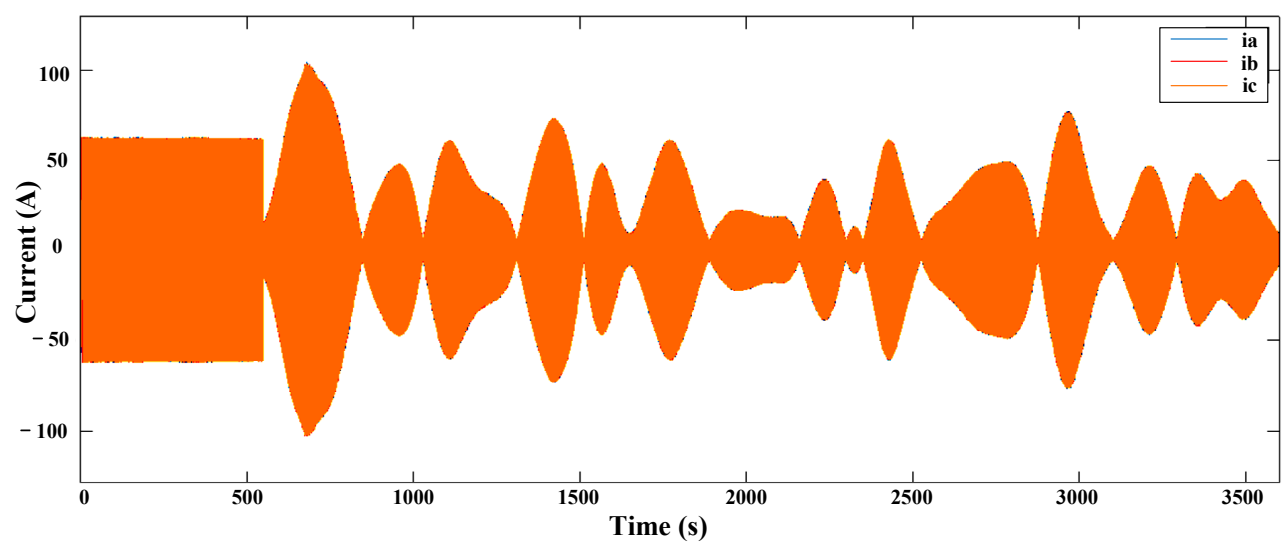

Figure 12. The three-phase current waveform.

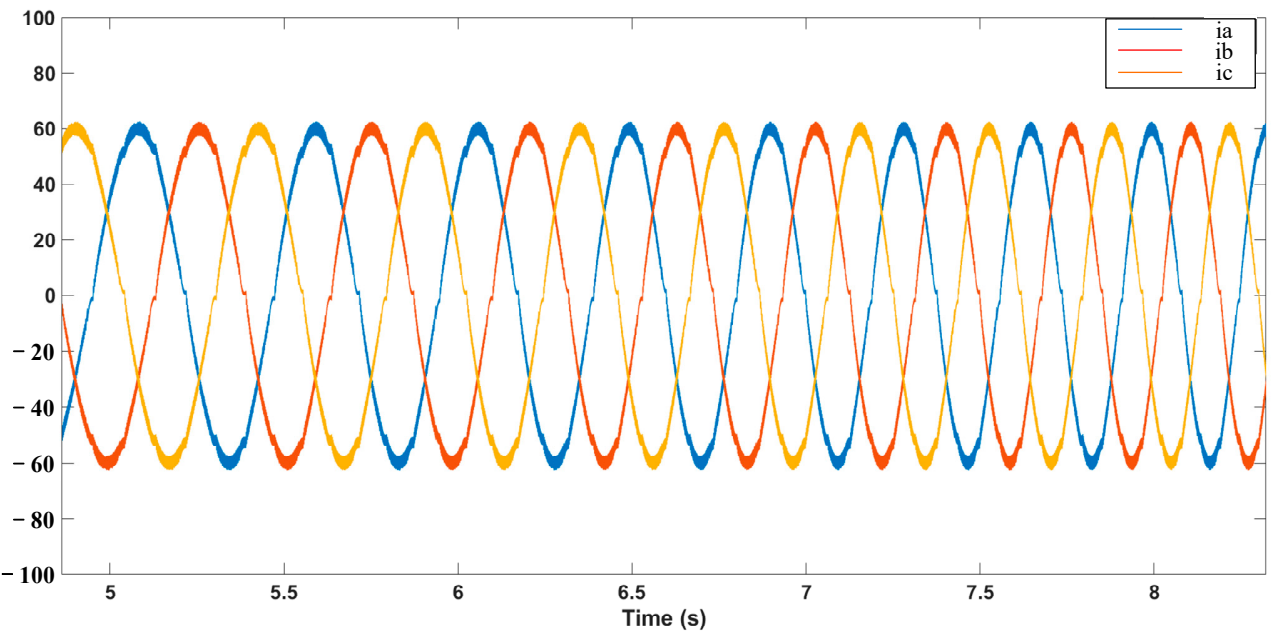

Figure 13. The enlarged part of the current waveform. 


\section{Economic, Social and Ecological Benefits}

Reviewing the development history of domestic wind power, Figure 14 shows the new domestic wind power hoisting situation [29]. The development of domestic wind power can be divided into two major development stages:

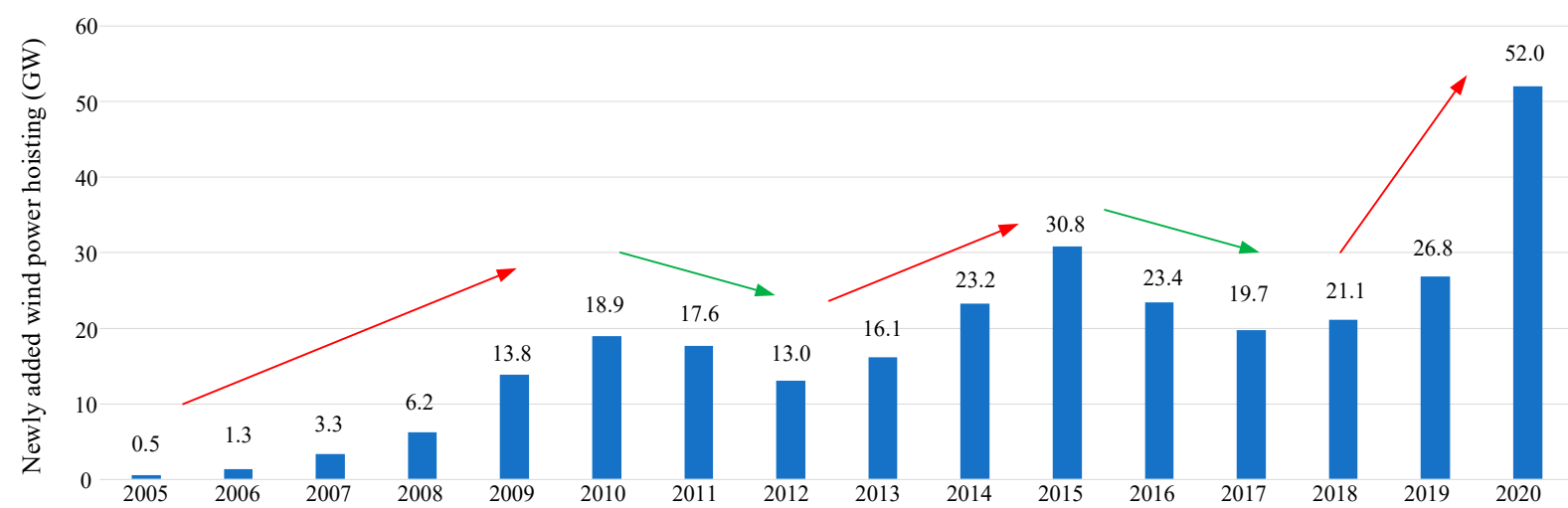

Figure 14. Domestic newly added wind power hoisting situation.

The first stage occurred in 2010 and earlier, a typical growth period. At this stage, the domestic wind power and wind power industry showed rapid development, driven by policies in the early stage of the industry's development.

The second stage occurred from 2011 to 2020 when the demand showed obvious cyclical fluctuations. From 2011 to 2020, policies dominated the development of the country's wind power industry. Among them, favorable and unfavorable policies are intertwined, resulting in obvious cyclical fluctuations in industry demand.

Summarizing the reasons behind the growth and decline of the domestic wind power industry in the past ten years, it is mainly due to the high level of domestic wind curtailment rate and certain fluctuations. It was not until 2019 that the domestic wind curtailment rate fell to less than $5 \%$. The high level of wind curtailment rate, on the one hand, inhibits the developers' enthusiasm for wind power investment; on the other hand, it urges regulators to strengthen supervision to solve the problem of wind curtailment. One of the main means is to control the supply of new wind power projects, which will negatively affect the newly installed capacity.

According to the national installed capacity of 400 million $\mathrm{kW}$ of new energy, flywheel energy storage with $3 \%$ of the installed capacity, and the cost of 2.5 yuan per watt after industrialization, the national market size will reach 30 billion yuan, the installed capacity of new energy will reach 800 million $\mathrm{kW}$, and the market size of flywheel energy storage will reach 60 billion yuan.

In 2020, the national curtailment of wind power was 16.61 billion $\mathrm{kWh}$, and the wind power utilization rate was $96.5 \%$, an increase of $0.5 \%$ annually, the abandonment of photovoltaic power was 5.26 billion $\mathrm{kWh}$, and the photovoltaic power generation utilization rate was $98.0 \%$, basically the same as in the previous year.

In the fourth quarter, the level of consumption and utilization of new energy across the country was relatively high, but the utilization rate of new energy declined annually. In the fourth quarter, the national abandonment of wind power was 4.97 billion $\mathrm{kWh}$, an annual increase of $23.3 \%$, and the utilization rate of wind power was $96.3 \%$, an annual decrease of $0.3 \%$. The utilization rate of PV power generation was $97.0 \%$, with an annual decrease of $0.6 \%$, and the level of new energy consumption and utilization was relatively high.

In recent years, owing to the large number of new energy installations, the reduction of the power grid has not kept up with the development of new energy, so the rate of wind curtailment has been rising. In this case, although there have been a series of measures implemented since 2018 to solve the wind curtailment problem, such as 'internal expansion and external transmission', the existence of new forms of energy storage is also necessary. 
From the experimental results, it can be concluded that FESS, as a new form of energy storage, will have a significant effect on reducing the wind curtailment rate.

At present, the FESS is still in the development stage, with a domestic market share of less than $1 \%$. However, as flywheel energy storage technology matures and costs decrease in the future, its role and economic benefits will become more prominent. Future scenarios include:

1. Promotion of large-scale price reductions of similar imported products and related technical equipment. According to the current scale of the flywheel energy storage market, this can save hundreds of millions of yuan each year.

2. Applying the FESS array parallel technology in the power grid can improve the security and power supply quality. It is expected that the economic benefits of the FESS array on the power supply quality of the power grid during the entire life cycle can reach hundreds of millions of yuan per year.

3. FESS can complete hundreds of thousands of charge and discharge cycles within its full life cycle, covering an area of only $50 \%$ of the traditional battery energy storage system, without discharging any toxic or harmful chemical materials, and is environmentally friendly.

\section{Conclusions and Future Work}

In this study, the FESS was used to compensate for the wind power discharge by a wind turbine in real-time, and a three-phase PMSM was used as the drive motor. The system used a double closed-loop control of speed and current in the start-up phase and the double closed-loop control of power and current in the power compensation phase. MRAS was used to estimate the speed of the flywheel rotor. The simulation effectively adjusted the wind power in real-time and verified the feasibility of using the FESS for wind power frequency modulation. The results show that applying the FESS to primary frequency modulation, such as wind and solar, has positive consequences. In the future, when demand for renewable energy power generation such as wind and solar greatly increases, using an array composed of multiple FESSs to perform primary frequency modulation on the actual output power of wind farms will prove reliable. The FESS plays a significant role in the frequency adjustment of the power grid.

Author Contributions: Conceptualization, Y.J. and Z.W.; methodology, Y.J.; software, Y.J.; validation, Y.J. and Z.W.; formal analysis, Z.W.; investigation, Y.J.; resources, Z.W.; data curation, Y.J.; writingoriginal draft preparation, Y.J.; writing—review and editing Z.W., J.Z. and P.Y.; visualization, Y.J.; supervision, Z.W., Z.Z. and P.Y.; project administration, Z.W. and Z.Z. All authors have read and agreed to the published version of the manuscript.

Funding: This research was funded by the Major Science and Technology Project in Inner Mongolia Autonomous Region under Grant 2020ZD0017 and Higher Education Scientific Research Project Inner Mongolia Autonomous Region under Grant NJZY21379.

Acknowledgments: The authors would like to thank the anonymous reviewers and the editor for their valuable comments and suggestions.

Conflicts of Interest: The authors declare no conflict of interest.

\section{References}

1. National Energy Administration's Guidance on Accelerating the Development of New Energy Storage. Available online: http: / / zfxxgk.nea.gov.cn/2021-07/15/c_1310079331.htm (accessed on 15 July 2021).

2. Lyu, X.; Di, L.; Lin, Z. On robustness of an AMB suspended energy storage flywheel platform under characteristic model based all-coefficient adaptive control laws. Front. Inf. Technol. Electron. Eng. 2019, 20, 120-130. [CrossRef]

3. Kapoor, D.; Deb, D.; Sahai, A.; Bangar, H. Adaptive failure compensation for coaxial rotor helicopter under propeller failure. In Proceedings of the American Control Conference 2012, Montreal, QC, Canada, 27-29 June 2012.

4. Nath, A.; Deb, D.; Dey, R. An augmented subcutaneous type 1 diabetic patient modelling and design of adaptive glucose control. J. Process Control 2020, 86, 94-105. [CrossRef] 
5. Lai, J.; Song, Y.; Du, X. Hierarchical Coordinated Control of Flywheel Energy Storage Matrix Systems for Wind Farms. IEEE/ASME Trans. Mechatron. 2017, 23, 48-56. [CrossRef]

6. Gong, L.; Wang, M.; Zhu, C. Immersion and Invariance Manifold Adaptive Control of the DC-Link Voltage in Flywheel Energy Storage System Discharge. IEEE Access 2020, 8, 144489-144502. [CrossRef]

7. Chang, X.; Li, Y.; Zhang, W.; Wang, N.; Xue, W. Active Disturbance Rejection Control for a Flywheel Energy Storage System. IEEE Trans. Ind. Electron. 2015, 62, 991-1001. [CrossRef]

8. Mir, A.S.; Senroy, N. Intelligently Controlled flywheel storage for wind power smoothing. In Proceedings of the 2018 IEEE Power \& Energy Society General Meeting (PESGM), Portland, OR, USA, 5-10 August 2018; pp. 1-5.

9. Meng, L.; Dragicevic, T.; Guerrero, J. Adaptive control of energy storage systems for power smoothing applications. In Proceedings of the 2017 IEEE 3rd International Future Energy Electronics Conference and ECCE Asia (IFEEC 2017-ECCE Asia), Kaohsiung, Taiwan, 3-7 June 2017; pp. 1014-1018.

10. Kapoor, D.; Sodhi, P.; Deb, D. Solar panel simulation using adaptive control. In Proceedings of the 2012 IEEE International Conference on Control Applications, Dubrovnik, Croatia, 3-5 October 2012; pp. 1124-1130.

11. Patel, R.; Deb, D.; Modi, H.; Shah, S. Adaptive backstepping control scheme with integral action for quanser 2-dof helicopter. In Proceedings of the 2017 International Conference on Advances in Computing, Communications and Informatics (ICACCI), Udupi, India, 13-16 September 2017; pp. 571-577.

12. Dong, Z.; Pan, Y.; Zhang, Z.; Dong, Y.; Huang, X. Model-free adaptive control law for nuclear superheated-steam supply systems. Energy 2017, 135, 53-67. [CrossRef]

13. Xingjian, D.A.I.; Kunpeng, W.E.I.; Xiaozhang, Z. A review on flywheel energy storage technology in fifty years. Energy Storage Sci. Technol. 2018, 7, 765-782.

14. Amiryar, M.E.; Pullen, K.R. A Review of Flywheel Energy Storage System Technologies and Their Applications. Appl. Sci. 2017, 7, 286. [CrossRef]

15. Goris, F.; Severson, E.L. A Review of Flywheel Energy Storage Systems for Grid Application. In Proceedings of the IECON 2018-44th Annual Conference of the IEEE Industrial Electronics Society, Washington, DC, USA, 21-23 October 2018; pp. 1633-1639.

16. Boztas, G.; Aydogmus, O. Design of a High-Speed PMSM for Flywheel Systems. In Proceedings of the 2019 4th International Conference on Power Electronics and their Applications (ICPEA), Elazig, Turkey, 25-27 September 2019; pp. 1-5.

17. Ghanaatian, M.; Lotfifard, S. Control of Flywheel Energy Storage Systems in the Presence of Uncertainties. IEEE Trans. Sustain. Energy 2018, 10, 36-45. [CrossRef]

18. Boukettaya, G.; Krichen, L.; Ouali, A. A comparative study of three different sensorless vector control strategies for a Flywheel Energy Storage System. Energy 2010, 35, 132-139. [CrossRef]

19. Abo-Khalil, A.G.; Eltamaly, A.M.; Alsaud, M.S. Sensorless control for PMSM using model reference adaptive system. Int. Trans. Electr. Energy Syst. 2021, 31, e12733. [CrossRef]

20. Karrari, S.; Baghaee, H.R.; De Carne, G.; Noe, M.; Geisbuesch, J. Adaptive inertia emulation control for high-speed flywheel energy storage systems. IET Gener. Transm. Distrib. 2020, 14, 5047-5059. [CrossRef]

21. Xiang, B.; Wang, X.; Wong, W.O. Process control of charging and discharging of magnetically suspended flywheel energy storage system. J. Energy Storage 2021, 47, 103629. [CrossRef]

22. Tziovani, L.; Hadjidemetriou, L.; Charalampous, C.; Tziakouri, M.; Timotheou, S.; Kyriakides, E. Energy Management and Control of a Flywheel Storage System for Peak Shaving Applications. IEEE Trans. Smart Grid 2021, 12, 4195-4207. [CrossRef]

23. Elbouchikhi, E.; Amirat, Y.; Feld, G.; Benbouzid, M.; Zhou, Z. A Lab-scale Flywheel Energy Storage System: Control Strategy and Domestic Applications. Energies 2020, 13, 653. [CrossRef]

24. Gayathri, N.S.; Senroy, N.; Kar, I.N. Smoothing of wind power using flywheel energy storage system. IET Renew. Power Gener. 2017, 11, 289-298. [CrossRef]

25. Hou, J.; Song, Z.; Hofmann, H.F.; Sun, J. Control Strategy for Battery/Flywheel Hybrid Energy Storage in Electric Shipboard Microgrids. IEEE Trans. Ind. Inform. 2021, 17, 1089-1099. [CrossRef]

26. Saleh, A.; Awad, A.; Ghanem, W. Modeling, Control, and Simulation of a New Topology of Flywheel Energy Storage Systems in Microgrids. IEEE Access 2019, 7, 160363-160376. [CrossRef]

27. Sebastián, R.; Peña-Alzola, R. Control and simulation of a flywheel energy storage for a wind diesel power system. Int. J. Electr. Power Energy Syst. 2015, 64, 1049-1056. [CrossRef]

28. Langston, J.; Steurer, M.; Schoder, K.; Borraccini, J.; Dalessandro, D.; Rumney, T.; Fikse, T. Power hardware-in-the-loop simulation testing of a flywheel energy storage system for shipboard applications. In Proceedings of the 2017 IEEE Electric Ship Technologies Symposium (ESTS), Arlington, VA, USA, 14-17 August 2017; pp. 305-311.

29. 2021 Wind Power Industry Research Report. Available online: https:/ /www.in-en.com/article/ (accessed on 16 November 2021). 